\title{
RELATO DE UMA EXPERIÊNCIA DE ENSINO DE LÍNGUA ITALIANA PARA A TERCEIRA IDADE: DESCONSTRUINDO CONCEPÇÕES E ARQUITETANDO UMA NOVA VISÃO DE MUNDO
}

\author{
REPORT OF AN EXPERIENCE OF TEACHING ITALIAN \\ LANGUAGE TO ELDERLY STUDENTS: DECONSTRUCTING \\ CONCEPTS AND CONSTRUCTING A NEW WORLDVIEW
}

\section{Sabrina de Cássia Martins*}

\begin{abstract}
RESUMO
O envelhecimento é um processo natural do ser humano, mas que socialmente acarreta exclusão do indivíduo da comunidade em que está inserido. De modo a contornar tal situação e reinserir o idoso na sociedade, instituições têm oferecido cursos especiais, com ênfase para os cursos de língua estrangeira (PEREIRA, 2005). O presente relato é fruto de uma experiência de ensino de língua italiana para alunos idosos, e tem como objetivo enfatizar os fatores motivadores que levaram tal público às aulas de língua estrangeira, suas crenças, dificuldades e necessidades, bem como a concepção do aluno idoso sobre a cultura da língua meta (HALL, 2011; KUMARAVADIVELU, 2012). Ressaltamos alguns conflitos que se mostraram evidentes em sala de aula e que estão em concordância com os estudos atuais.
\end{abstract}

Palavras-chave: Ensino de língua estrangeira, língua italiana, idoso.

\section{ABSTRACT}

Ageing is a natural process undergone by every human being. However, it also brings about social exclusion among older people in the communities to which they belong. Seeking to address this situation and find ways to reintegrate the elderly into society, institutions have provided special courses, particularly for foreign language learning. This report results from the experience of teaching Italian to older students, and it aims to spotlight the motivating factors that brought these learners to foreign language lessons, and also their beliefs, difficulties, needs, as well as their conception of target language culture. Here we highlight some of the conflicts that were evident inside the classroom and that are in line with current studies.

Keywords: Foreign language learning, Italian language, elderly.

\footnotetext{
* Universidade Estadual Paulista Júlio de Mesquita Filho/IBILCE,São José do Rio Preto, SP. Brasil. sabrismartins@gmail.com
} 


\section{INTRODUÇÃO}

O mundo está envelhecendo, e o Brasil é um dos países que mais sofrem tal processo na atualidade. Pesquisas indicam que o número de idosos irá triplicar nos próximos quarenta anos e, no Brasil, dados do IBGE mostram que, na última década, o número de idosos já correspondia a 10,8\% da população, percentual que poderá chegar a $15 \%$ até 2030.

Embora o envelhecimento seja um processo natural do ser humano, isso acarreta a consequente exclusão do idoso não só no ambiente profissional, sob o argumento da superação da idade produtiva, como também do convívio social. A situação de exclusão acaba por conferir à palavra idoso um sentido pejorativo de incapacidade ou inutilidade, por isso, na grande maioria dos casos, o indivíduo não admite estar envelhecendo.

Ancorada em tais fatores, essa fatia da população tem buscado cada vez mais aumentar sua qualidade de vida e, consequentemente, sua contribuição para a sociedade. Isso inclui novos desafios, novas oportunidades, novas atividades (sejam físicas ou intelectuais), criando um novo sentido para a denominação terceira idade, ou até mesmo um novo termo: melhor idade. A sociedade, por sua vez, percebeu que pode se beneficiar do mercado que envolve tal público.

Uma das formas de reinserção do idoso é a abertura de cursos para sua capacitação profissional e adequação no que diz respeito à ciência e à tecnologia. Essa atitude baseia-se no pressuposto de que a idade não é um empecilho para aprender. Antes, o saber acumulado complementa a formação do indivíduo idoso e, não obstante, faz com que ele retome antigos projetos e crie novos, o que demonstra a sua capacidade em vencer desafios.

É nesse contexto de mudança de concepção do que seja envelhecer, assim como do papel do idoso e da sociedade para com este, que diversas universidades têm aberto suas portas para esse público, de modo a cooperar efetivamente para a sua reinserção na sociedade. Sem dúvida, dentre os cursos oferecidos pelas instituições, os mais procurados são os de língua estrangeira. Isso porque, como bem ressaltado por Pereira (2005), o aprendizado de outro idioma induz ao exercício intelectual do ser humano, renovando a atividade cerebral e retardando possíveis degenerações.

Para além de um processo mental que visa à aquisição e ao conhecimento das estruturas linguísticas que compõem a língua estrangeira (L2), seu aprendizado é um processo social que provém da interação, uma forma de contato entre os membros de uma comunidade que incita o reencontro ou até mesmo a reconstrução 
da identidade do indivíduo. Assim, aprender uma língua estrangeira estimula o convívio social e promove o convívio com outras pessoas, culturas e opiniões.

O presente trabalho tem como objetivo relatar algumas situações verificadas durante uma experiência de ensino de língua estrangeira, no caso, a língua italiana, para alunos idosos que frequentam a Universidade Aberta à Terceira Idade (UNATI) de uma universidade pública do interior do estado de São Paulo. Para tanto, primeiramente, serão discutidos alguns temas frequentes nos estudos da área e que devem ser considerados em sala de aula para o sucesso do ensino-aprendizagem de línguas estrangeiras, tais como as crenças desses alunos, seus valores e o que os motiva a aprender, delineando, assim, o perfil do aluno privilegiado. Em um segundo momento, será abordada a importância do conceito de cultura para o ensinoaprendizagem de línguas, apontando para o papel do processo de globalização cultural ao qual o ser humano é subordinado atualmente na criação de estereótipos, para então ser exposta a forma como todas essas questões se manifestaram no decorrer do curso.

Importa ressaltar que este estudo não visa ditar regras para o ensino de língua estrangeira para idosos, muito menos criticar métodos ou materiais didáticos. Antes, tem por finalidade relatar uma experiência de ensino, expondo alguns momentos em sala de aula que refletiram a sensação de dever cumprido, ou seja, de haver despertado nesses alunos o amor pela língua italiana e pela cultura desse país tão fascinante que é a Itália.

\section{ENSINO DE LÍNGUAS E O PERFIL DO ALUNO IDOSO}

Ao longo da história da Linguística Aplicada e, em particular, de sua vertente que trata do ensino de línguas estrangeiras, podemos observar diversas mudanças de paradigma teórico e metodológico. Apesar disso, existe ainda, segundo Hall (2011), uma tendência, nesse domínio, a tratar as aulas de L2 como homogêneas, ignorando as características individuais dos alunos, como interesse, motivação, atitudes e até mesmo a idade e a personalidade de cada um.

Tal fato, salienta o autor, reflete as próprias teorias de aquisição e aprendizagem de línguas que têm - ou pelo menos tiveram durante muito tempo - como foco as características em comum dos alunos quando aprendendo uma segunda língua. Dessa forma, esquece-se de que o aluno é, acima de tudo, um ser histórico, um indivíduo que traz consigo para a sala de aula suas próprias experiências que diferem 
de contexto para contexto e que constituem sua identidade e sua posição em relação à língua estrangeira.

Kumaravadivelu (2012) argumenta que as necessidades, a motivação e a autonomia do aluno são determinadas pela combinação de fatores individuais, institucionais, governamentais e sociais, elementos que tornam a sala de aula um ambiente complexo e desafiador. Além disso, cada aluno tem um papel fundamental no ensino/aprendizado de línguas, pois é só por meio de sua colaboração que se chegará à produtividade dentro da sala de aula. Para o estudioso, é o aluno quem decide se vai ou não aprender e o que irá aprender, de modo a complementar os esforços do professor. Este, por sua vez, precisa estar ciente das necessidades do primeiro para conduzir da melhor forma o ensino, abordando sempre as particularidades da situação.

No tocante ao período mais adequado para se aprender uma segunda língua, parece haver um choque de opiniões e, embora haja consenso sobre a influência da idade sobre o aprendizado de línguas, questões que abordam a problemática da melhor fase, as diferenças nas estratégias de ensino e o efeito da idade no aprendizado ainda não foram totalmente respondidas.

Durante muito tempo foi defendido que quanto mais jovem o aluno, melhores seriam os resultados da aprendizagem. Atualmente, a hipótese de que a velocidade de tal processo diminua com o passar dos anos tem sido contestada. Os contra-argumentos dessa proposição fundamentam-se no fato de que as experiências vivenciadas modelam o cérebro. Além disso, a neurociência advoga que o surgimento de novas células cerebrais independe da idade, mas sim de ambientes ricos em estímulos. Tais argumentos estão em concordância com os estudos em gerontologia, que têm demonstrado que as conexões entre os neurônios não são fixas e, assim como algumas podem ser eliminadas com o decorrer dos anos, outras podem surgir (PEREIRA, 2005). Ademais, é preciso considerar o nível intelectual e cultural do aluno, bem como suas motivações e objetivos.

É sabido, entretanto, que as necessidades de cada faixa etária diferem, por isso, as metodologias utilizadas em sala também variarão de acordo com a idade do aluno. Sem dúvida, é indiscutível que se por um lado a criança pode chegar a desenvolver uma fluência muito próxima à do falante nativo no que diz respeito à pronúncia, por outro, o aluno adulto tem mais facilidade com o vocabulário e com as estruturas da língua, pois as células neurais responsáveis pela compreensão de relações semânticas e gramaticais se desenvolvem com a idade (SCHLEPPEGRELL, 1987). Tal facilidade deve-se ao fato de o aluno adulto já ter desenvolvido seu sistema cognitivo e, por isso, ser capaz de fazer associações e generalizações. 
Além do mais, o aluno idoso tem ainda a vantagem de trazer para dentro da sala de aula todo o seu conhecimento, bem como suas experiências prévias e sua motivação interna que irão direcionar a sua reflexão (SERRONHA, 2010). Ele busca satisfazer suas necessidades pessoais, seja por autonomia, seja para melhorar a autoestima, na tentativa de superar seus desafios. É um indivíduo agente na construção do seu conhecimento e na reconstrução de sua identidade a partir da sua abertura para novas experiências e concepções de mundo. Esse público vai para a aula de línguas não apenas para ocupar o seu tempo livre, mas, sobretudo, para se reinserir na sociedade fazendo amizades, dividindo experiências e compartilhando suas histórias. A seguir, serão abordados os valores, crenças e motivações do aluno idoso.

\subsection{0 aluno idoso, seus valores e a afetividade}

É de comum acordo que todo o ser humano constrói durante as primeiras fases de sua vida um conjunto de princípios abstratos (caracterizados por traços culturais, ideológicos, morais, institucionais que o indivíduo compartilha com a comunidade em que se insere) que guiarão suas escolhas e atitudes ao longo de sua vida. A esses princípios dá-se o nome de valores e sua formação deve-se aos diversos contextos situacionais vivenciados pelo sujeito.

No ensino de línguas para alunos de idade avançada é recorrente a presença de valores, tais como o respeito pelo professor e pela disciplina ministrada, a necessidade de dedicação e o agradecimento ao professor. Se por um lado os valores impulsionam o enaltecimento da situação de ensino e aprendizagem em sala de aula, por outro, influenciam no estabelecimento de crenças que podem levar ao fracasso de tais processos.

Tais valores já estão fixos na mente do aluno idoso e se "é relativamente fácil incutir valores a uma criança, o mesmo não se pode dizer de um adulto, que vê, frequentemente, o que lhe é estranho ou desconhecido como uma ameaça" (SERRONHA, 2010, p.9). Tal assertiva deve-se à concepção de que o aprendiz já construiu no decorrer do tempo suas concepções sobre a forma como interpretar o mundo. Essas percepções direcionam a visão de ensino e aprendizagem, determinando a resistência ao novo.

Nascente (2006), retomando os pressupostos de Ehrman (1996), atribui as dificuldades de aprendizado pelos idosos também aos níveis de afetividade. Uma vez que esta e a cognição se inter-relacionam, ambas influem no desenvolvimento do indivíduo. Por exemplo, quando estudamos uma língua estrangeira, a cultura da 
língua em questão pode influenciar na afetividade que será cultivada pelo aluno para com a L2, ativando os mecanismos cognitivos que determinarão se o conteúdo será aprendido mais fácil e naturalmente, caso o aluno desenvolva uma atitude positiva perante a língua, ou não. Assim, a abertura para o aprendizado de outras línguas e a convivência com outras culturas são o primeiro passo em direção à libertação de preconceitos e construção de novos valores.

Por fim, enfatizamos que o acesso a outras culturas influencia no desenvolvimento do ser humano e, por conseguinte, na reconstrução de seus valores que, aliados à afetividade ao universo linguístico e cultural em apreço, nortearão o andamento do processo de aprendizagem. Por isso, é importante que o educador saiba reconhecer e utilizar os diferentes valores presentes dentro da sala de aula, a fim de corroborar o sucesso do processo de ensino-aprendizagem.

\title{
1.2. 0 aluno idoso e sua motivação
}

A motivação é considerada uma das chaves para o sucesso no ensino/ aprendizagem de línguas para qualquer aluno, mas em especial para o aluno idoso. Visto que a presença (ou ausência) de motivação determina as conquistas ou insucessos no aprendizado, ela é considerada um dos desafios do professor de línguas, pois muitas vezes é esperado que ele a desenvolva nos seus alunos.

Segundo o Houaiss (2009), a motivação pode ser definida como um "conjunto de processos que dão ao comportamento uma intensidade, uma direção determinada e uma forma de desenvolvimento próprias da atividade individual", em outras palavras, é a motivação, influenciada pelo contexto sociocultural que direciona nossas emoções e atos a fim de que alcancemos nossos objetivos, seja a curto ou em longo prazo. Ela depende do contexto e muda de aluno para aluno, sendo, portanto, dinâmica.

Para Schütz (2003, p.1)

\begin{abstract}
A motivação é uma força interior propulsora, de importância decisiva no desenvolvimento do ser humano. Assim como na aprendizagem em geral, o ato de se aprender línguas é ativo e não passivo. Não se trata de se submeter a um tratamento, mas sim de construir uma habilidade. Não é o professor que ensina nem o método que funciona; é o aluno que aprende. Por isso, a motivação do aprendiz no aprendizado de línguas é um elemento chave.
\end{abstract}

Sua fonte pode estar conectada a vários fatores, tais como o interesse por outras culturas, necessidade (trabalho ou viagem), passatempo, turismo etc. Lieb (1999 apud VINTRÓ DE DEUS, 2007) aponta como possíveis fatores motivadores: 1. As relações sociais, já que a aula de língua também ajuda no aumento de redes 
de relacionamento; 2. As expectativas externas, por exemplo, alcançar um objetivo profissional; 3 . As expectativas internas, por exemplo, alcançar algum objetivo pessoal 4. Por fim, uma forma de escape para as tensões do dia-a-dia, uma distração ou uma forma de relaxar.

Segundo Schütz (2003), a motivação advém, sobretudo, de fatores internos, isto é, para fins de satisfação de necessidades. O autor cita como exemplo a necessidade de integração em um ambiente onde se fala uma língua estrangeira, e de fatores externos, que correspondem às características do ambiente que frequentamos. $\mathrm{O}$ autor destaca a importância da autenticidade do ambiente e das atividades direcionadas aos interesses do aluno para o aumento da motivação.

Baseando-se em Gardner (1985), Hall (2011) menciona duas orientações para a motivação: a primeira é a integrativa, e deriva da identificação do aluno com a cultura meta, resultando no interesse por parte do aluno em aprender uma segunda língua, a fim de poder se integrar culturalmente com os membros de tal comunidade; a segunda é a instrumental, considerada de ordem pragmática, uma vez que deriva do desejo de conquista de um objetivo, por exemplo, superar um exame ou conseguir um emprego. Segundo o autor, estudos têm relatado a supremacia da primeira em relação à segunda, embora as duas orientações não se excluam, tampouco indiquem maior ou menor nível de motivação.

O mesmo autor também aponta para o fato de os alunos fazerem uso de motivações intrínsecas, isto é, que vêm do interior do indivíduo, resultando no prazer em se aprender a língua, e de motivações extrínsecas, ou seja, que vêm de fora do aluno e que derivam da necessidade em se aprender a língua. Kumaravadivelu (2012) ressalta que assim como tudo o que é intrínseco é inato ao ser humano, também a motivação intrínseca o é, mostrando-se importante para o seu comportamento; já a motivação extrínseca, por estar relacionada a fatores externos ao indivíduo, é condicionada por situações que provocam esforço, sucesso e fracasso. Concordando com os autores anteriormente citados, Kumaravadivelu (2012) ressalta que as duas vertentes de motivação não se excluem, porém parece haver a sobreposição da motivação intrínseca sobre a extrínseca.

Concernente à motivação no ambiente de sala de aula, pode-se dizer que esta provém de uma série de fatores internos e externos, como ressaltado por Hall (2011). Os internos relacionam-se ao interesse pela tarefa, à relevância da atividade para o aprendizado, ao autocontrole do aprendizado, à sensação de progresso, à autoestima, à confiança, à ansiedade e à expectativa de sucesso, à idade, à aptidão e ao gênero. Já os fatores externos, também de acordo com o autor, relacionam-se ao contato e interação com pessoas importantes para o aprendizado, tais como 
colegas de classe, família e professores, às correções, aos elogios, ao ambiente de aprendizado, ao contexto externo, o que inclui as relações familiares e as normas sociais.

Além da motivação, também a autoestima exerce um papel importante no aprendizado de uma L2, destacando-se como uma qualidade essencial do aprendiz de línguas estrangeiras, uma vez que dela dependerá a atitude do aluno em sala de aula, que poderá se demonstrar inibido, extrovertido, empático, ansioso etc. Tais qualidades determinarão o sucesso ou até mesmo o fracasso no processo de aprendizagem. Um aluno com a autoestima elevada também amplia sua motivação para aprofundar seu conhecimento, adquirindo segurança para realizar tarefas mais complexas e, consequentemente, para intensificar a interação em sala, pois se o aluno não se sente seguro, a desmotivação entra em cena e abre caminho para o desinteresse e para o fracasso do aprendizado.

Para Kumaravadivelu (2012), o desempenho do aluno depende profundamente das expectativas em relação ao aprendizado que, concernente ao aluno idoso, estão relacionadas principalmente à crença de que é possível aprender uma língua rapidamente sem que para tanto seja preciso dedicar seus esforços. Geralmente essa visão é reforçada durante o nível básico, que costuma fluir mais facilmente para o aluno de línguas, e é distorcida a partir do nível intermediário, quando o aluno se depara com seus erros, que destroem a convicção de fluência, percebendo as complexidades da língua em questão (HALU E PARANÁ, 2007).

Para que os alunos se sintam mais motivados, cabe ao professor ajudá-los a identificar seus êxitos e refletir sobre seu progresso, além de trabalhar para a integração do aluno com a segunda cultura. Contribuir para a autonomia do aluno também é uma estratégia para manter o aluno motivado. Assim, a opção de escolha sobre argumentos a serem trabalhados em sala, exercícios, a oportunidade de compartilhar experiências, são formas de aumentar a motivação do aluno idoso.

\subsection{0 aluno idoso e suas crenças}

De acordo com Barcelos (2004), o início das pesquisas direcionadas às crenças, em Linguística Aplicada, data de meados da década de 80, embora tenham atraído os estudiosos brasileiros apenas na década seguinte, quando, segundo a autora, ocorreu uma mudança de foco nos estudos da área do produto para o processo, sendo que dentro deste o aprendiz passa a exercer um papel fundamental. $\mathrm{O}$ interesse pelo universo do aprendiz ganha força com a abordagem comunicativa, que dedicou 
"uma preocupação maior em entender toda essa bagagem que o aprendiz traz para a sala de aula e para a experiência de aprender línguas" (BARCELOS, 2004, p.127).

Segundo a autora acima citada, em Linguística Aplicada existem vários termos e definições para o conceito de crença, o que torna sua investigação ainda mais complexa, mas de um modo geral, todas as definições enfatizam que "as crenças se referem à natureza da linguagem e ao ensino/aprendizagem de línguas" (BARCELOS, 2004, p.132). Ademais, algumas das definições abordam seu aspecto cultural e social, ressaltando sua importância na interpretação das experiências, possibilitando a reflexão sobre o mundo a nossa volta.

A autora acrescenta que as crenças estão interligadas com a motivação e são consideradas determinantes no aprendizado de línguas, pois guiam a forma como os alunos pensam e agem. Dentro da sala de aula, as crenças estão relacionadas especialmente 1. ao papel do aluno e do professor, 2. à concepção de língua e 3 . à concepção de ensino e aprendizagem.

É sabido que alunos idosos são dotados de crenças consolidadas sobre o seu aprendizado e a forma como este deve ser orientado. Com efeito, o aluno idoso já passou por diversas experiências de ensino-aprendizagem, não apenas em língua estrangeira, mas também em outras áreas, o que inclui também experiências no lado oposto, isto é, como professor. A sua vivência pessoal influencia na construção de tais crenças e na interpretação do momento presente.

Como bem afirma Oliveira (2008), "eles [os alunos] vêm para as aulas com uma bagagem no que se refere às concepções sobre o que seja aprender uma língua estrangeira. Negativas ou positivas, essas convicções alteram o processo de dimensão de aprender o idioma". Trata-se de uma cultura de aprendizagem que muitas vezes acaba por influenciar o aprendizado do aluno ou até mesmo corroborar a sua estagnação ou, na pior das hipóteses, o seu retrocesso. Dentre os campos mais associados às crenças estão a forma e função das correções, o papel da tradução, dos exercícios e da repetição, a importância da gramática e, claro, a mais enraizada na mente do aluno idoso, a idade mais adequada para se aprender uma língua.

Citando Ellis (1994), Halu e Paraná (2007) fazem menção à hipótese do perído crítico, muito divulgada durante os anos 60 , a qual defendia que há um limite de idade para que o aprendizado de línguas ocorra de forma natural, estando o aluno sujeito a limitações de aprendizagem gramaticais e lexicais, tanto na escrita quanto na fala. A versão forte destaca ainda que seria impossível o aprendizado bem sucedido após os doze anos. Entretanto, Oliveira (2008) assevera que o fator idade não afeta a faculdade da linguagem e que a hipótese do "período crítico" é discutível, já que um aprendiz que tenha iniciado seu aprendizado em uma língua estrangeira já na idade 
adulta pode sim alcançar a fluência na língua. Portanto, entendemos que, embora haja a redução das competências, isso não impossibilita o aprendizado.

O fato é que tal hipótese alimenta a crença de que adultos apresentam maiores dificuldades no aprendizado, servindo ainda como justificativa para sua falta de êxito. Assim, o aluno adulto ampara-se nesses conceitos difundidos que nutrem as crenças para justificar sua acomodação ou até mesmo sua desistência, o que torna frequente a presença de comentários como "estou muito velho para aprender", "burro velho não pega marcha", "não tenho facilidade pra aprender línguas". E isso ocorre justamente

(...) no nível no qual o aluno mais precisa estar consciente de sua responsabilidade no processo, e adotar atitudes mais autônomas na condução de seu aprendizado, ele se arma desses pseudoconceitos teóricos esperando, engessado numa postura tradicional, que o professor continue assumindo o controle do aprendizado. (HALU E PARANÁ, 2007, p.47)

Entretanto, é importante ressaltar que as classes não são homogêneas e que as crenças variam de aluno para aluno, a depender de sua idade, classe social, contexto e experiências, o que caracteriza a complexidade desse ambiente. O professor, por sua vez, está no centro dessa complexidade e se encontra na posição de ter que saber lidar em sala com as diferentes crenças dos alunos e com conflitos entre estas e as suas próprias crenças, bem como direcionar suas aulas de modo a explorá-las por meio de estratégias que provoquem a reflexão e que permitam ultrapassar essa barreira.

\section{GLOBALIZAÇÃO, CULTURAS E HABILIDADE INTERCULTURAL}

De acordo com Kumaravadivelu (2008, p. 32), o conceito de globalização é transdiciplinar e, em poucas palavras, pode ser definido como uma força que delineia as novas formas de interconexões entre as nações, economias e povos. Como resultado, temos uma transformação que atinge diretamente a vida social contemporânea nas suas dimensões política, econômica, cultural, tecnológica, ecológica e individual. Em suma, a globalização é formada por processos sociais que criam, multiplicam, aproximam e intensificam as trocas e interdependências sociais globais. Uma das características mais evidentes do processo de globalização é a unificação no que diz respeito à cultura.

Para Kramsch (2010) noção de cultura é entendida como um agrupamento de indivíduos que compartilham de uma história, uma língua padrão e imagens. A autora defende que o conceito de cultura hoje é caracterizado pela subjetividade e 
historicidade, sustentando-se pelos discursos que dão sentido à nossa vida. Assim, a noção de discurso ocupa considerável importância nos estudos em Linguística Aplicada, uma vez que é pelos discursos que construímos sentidos, isto é, que produzimos significados mediante o sistema simbólico que é a língua. É por meio deles que as tradições se mantêm, que a sociedade se ampara e que os indivíduos expressam sua subjetividade. Kramsch (2010) argumenta que os sentidos não existem antes que sejam articulados na língua e esta, por sua vez, é sempre histórica e socialmente localizada nos discursos que organizam os sentidos de acordo com as possibilidades fornecidas pelo sistema.

Em contrapartida, a globalização cultural refere-se ao processo de circulação cultural ao redor do planeta, em especial, à forma como o contato entre povos e suas culturas - suas ideias, valores, estilo de vida - os aproxima (KUMARAVADIVELU, 2008). Assim, não existem mais ilhas culturais e as culturas estrangeiras deixaram de ser estrangeiras para se incorporarem à nossa cultura. Nesse sentido, se num passado não muito distante o conceito de cultura representava tradições, memórias históricas e o compartilhamento de experiências que davam sentido ao mundo, atualmente, o conceito de cultura está associado muito mais a ideologias, atitudes e crenças criadas e manipuladas pela mídia, Internet e a indústria de marketing. Trata-se de uma cultura fragmentada em estereótipos manipulados que têm como objetivo único garantir interesses privados (KRAMSCH, 2010).

No que diz respeito à influência da globalização cultural no ensino de línguas, pode-se dizer que este é o local em que a autoidentidade e a subjetividade se constroem, em que as diferentes línguas e culturas estão em contato. Para Kumaravadivelu (2008), em tempos de intensa globalização cultural, a identidade individual só pode ser construída por meio de uma consciência cultural global. Portanto, é imprescindível que os alunos de língua estrangeira adquiram tal consciência a fim de enfrentar os desafios do século XXI. Em texto posterior (KUMARAVADIVELU, 2012), o estudioso salienta que a globalização cultural tem proporcionado oportunidades para o crescimento cultural, como também ameaças para a nossa identidade cultural e nacional. A consciência da necessidade de se aprender outras línguas tem também despertado a convicção de que é preciso preservar a nossa identidade. Desse modo, a formação de identidades no mundo global requer conhecimento crítico para reconhecer as diferenças entre informação e desinformação, bem como ideias e ideologias.

Segundo Kumaravadivelu (2008), a cultura sempre foi considerada um subproduto do aprendizado de uma língua que fornecia ao aluno uma cultura alvo, não tendo recebido devida importância antes dos anos 90, quando se intensificaram 
os fluxos migratórios e o interesse pelo multiculturalismo. $\mathrm{O}$ argumento para se ensinar cultura é que os aprendizes de uma língua estrangeira precisam saber que vivemos em um mundo complexo e que a compreensão de outras culturas é essencial no desenvolvimento de cidadãos do novo milênio. Nesse contexto, ascende o termo interculturalidade, conceito que releva a consciência intercultural, isto é, a consciência entre as similitudes e as diferenças entre a cultura de partida e a cultura de chegada.

As tendências mais recentes no Ensino de Línguas enfatizam que o aprendiz de língua estrangeira necessita ser interculturalmente competente, o que para Kramsch (2010) significa refletir sobre práticas discursivas entre falantes de diferentes línguas, questionando 1 . os interesses dos textos, 2. a possibilidade de algumas palavras em detrimento de outras, 3. o posicionamento do falante, 4. a estruturação dos eventos descritos, e 5. de quais discursos prévios lança mão. Jim e Cortazzi (1998) salientam que a aprendizagem de habilidades interculturais sempre foi menos enfatizada e a cultura do aluno e sua relação com a cultura alvo raramente tem sido considerada, fato que causa um efeito profundo na forma como professor e alunos percebem a aprendizagem de línguas e como avaliam seus papeis em sala.

De fato, como bem argumentam os autores, a ação de aprender uma língua estrangeira requer dos alunos consciência da sua própria cultura no processo de aprendizagem para proporcionar o desenvolvimento de habilidades interculturais. Kramsch (2010) propõe então o conceito de esfera de interculturalidade, uma metáfora para a capacidade de reconhecer o contexto histórico dos discursos e suas intertextualidades, assim como a habilidade de resignificar, reestruturar, re- e transcontextualizar os discursos e jogar com a tensão entre texto e contexto.

Em suma, todos esses autores defendem a necessidade do desenvolvimento por parte do indivíduo de uma abertura em aprender, entender e valorizar a cultura do outro sem que para tanto ele perca sua identidade cultural. Por isso, o aluno interculturalmente competente assume uma posição mediana entre a sua própria cultura e a cultura da língua estrangeira que lhe permite analisá-las, compreendêlas, além de negociar a construção de novas identidades baseadas no respeito ao que lhe é novo. Por fim, retomando as palavras de Salomão (2012), o indivíduo interculturalmente competente entende que a diversidade cultural implica aceitar a diferença e, sobretudo, compreender o que ela oculta.

\subsection{Cultura x cultura e a criação de estereótipos}

Como dito anteriormente, definir o termo cultura é uma tarefa complexa, isso porque tal palavra tem sido utilizada no decorrer da história em diversas áreas do 
conhecimento, por distintas e incompatíveis formas de pensar. Uma dessas áreas é a Sociologia que, equiparando tal conceito ao de civilização, distingue Cultura de cultura. A primeira refere-se às atividades de um povo, isto é, arte, arquitetura, teatro, dança, música, literatura, constituindo o seu progresso intelectual, já a segunda refere-se a crenças, moral, costumes, normas e valores que governam a vida cotidiana.

De fato, o que a cultura proporciona a uma determinada comunidade ou aos seus indivíduos, segundo Geertz (1973/2000 apud KUMARAVADIVELU, 2008), são estruturas psicológicas, ou melhor, um sistema simbólico historicamente transmitido que direciona o comportamento do indivíduo. Além do mais, tais estruturas psicológicas são a base para a formação da identidade e do desenvolvimento do senso de solidariedade para com os integrantes de outras comunidades; modelam as aspirações e atitudes com relação ao eu e a sociedade, delimitando os direitos e as responsabilidades dos indivíduos. Não obstante, tais estruturas também formam preconceitos e estereótipos.

De acordo com Kumaravadivelu (2008), o sentido original do termo estereotipar significa a replicação de uma imagem padronizada, concepção estendida para o comportamento humano, referindo-se à forma como a sociedade categoriza as pessoas por meio de um conjunto rígido de características compartilhadas ou não. O estereótipo, por sua vez, é uma imagem social, muitas vezes falsa ou errônea, que construímos por meio de uma descrição simplificada sobre um povo e que é fixada através do tempo.

Ainda segundo o autor, os estereótipos são uma versão exagerada da realidade ao ponto de distorcê-la, transformando-a numa imagem simples e que, portanto, torna uma comunidade superior à outra. Assim, uma vez formado o estereótipo, um indivíduo não se esforça mais para entender o outro em sua complexidade. Entendido como crenças e valores de uma sociedade ou comunidade em relação à outra, o estereótipo pode se transformar, na sua forma extrema, em preconceito e discriminação, culminando em ódio e, consequentemente, violência.

Questionando-se sobre as causas da formação de estereótipos, o referido autor cita algumas teorias sócio-psicológicas que tentam responder a tais questões. A primeira delas argumenta que são derivados de um sistema racista incorporado à sociedade atual; a segunda defende que tal formação ocorre quando a nossa autoestima está ameaçada; a terceira afirma que os estereótipos culturais resultam de uma oposição binária entre o nós e eles, que produz uma visão essencialista e estática do outro. Para o ensino-aprendizagem de língua italiana, é fundamental que compreendamos o conceito de cultura e, sobretudo, da formação e fixação 
de estereótipos, pois na grande maioria dos casos são estes que influenciam primordialmente o interesse do aluno pela língua.

A seguir, será descrita uma experiência de ensino para alunos da terceira idade no curso de língua italiana oferecido pela UNATI por uma universidade pública do interior paulista; posteriormente, será discutida a forma como os estereótipos compunham a mente dos alunos que participaram desse curso, influenciando na motivação em aprender a língua.

\section{UMA EXPERIÊNCIA DE ENSINO DE LÍNGUA ITALIANA PARA A TERCEIRA IDADE}

Como dito anteriormente, o presente estudo tem sua origem em uma experiência de ensino para alunos da terceira idade transcorrida no primeiro semestre de 2013, quando surgiu a oportunidade de ministrar um curso de língua estrangeira para a UNATI - Universidade Aberta à Terceira Idade -, que poderia ser tanto para fins instrumentais, por exemplo, turismo, ou convencional, em qualquer um dos níveis (básico, intermediário ou avançado). Foi proposto, então, um curso de língua italiana para alunos iniciantes, às segundas-feiras, das $14 \mathrm{~h} 30 \mathrm{~min}$ às $16 \mathrm{~h} 30 \mathrm{~min}$, com duração de quatro meses (março a junho), que recebeu a denominação de Lingua italiana - Básico 1 e contou inicialmente com 15 inscritos, número este que sofreu variações no decorrer do semestre, como será explanado a seguir. Nas próximas linhas, serão relatadas algumas situações que refletem o discutido previamente.

Situação 1: Primeira aula: motivações e objetivos

Assim como em qualquer disciplina, a primeira aula é sempre um momento de apresentações. Nesse caso, foram duas horas de conhecimento recíproco que possibilitou o estabelecimento de um vínculo entre o professor e seus alunos. Visto que a motivação é um elemento chave no ensino-aprendizado de línguas (SCHÜTZ, 2003), para o sucesso desse processo, o professor precisa estar atento aos motivos que levaram seus alunos a aprender a língua que ele leciona. Ademais, ao expor os fatores que motivaram suas escolhas ao longo da vida, que contribuíram para sua evolução profissional e que resultaram em experiências positivas, o professor não apenas semeia a motivação, mas também contribui para o interesse do aluno em aprender. 
Dentre os motivos por eles mencionados, o turismo foi o mais frequente. Muitas daquelas pessoas estavam se preparando para viajar para a Itália no meio do ano e outras demonstraram o desejo de visitar o país em algum momento de um futuro próximo. Merece destaque a fala de uma senhora que revelou um motivo especial: sua família (filha, genro e neta) havia se mudado para a Suíça a trabalho e como a criança estava aprendendo a língua italiana na escola, a avó decidiu estudar também para poder se comunicar com a netinha na língua em questão. Alguns não expressaram um motivo bem definido, afirmando que era uma forma de preencher o tempo livre e aprender algo novo. De um modo geral, ficou evidente que o interesse pela língua e pela cultura italiana estava diretamente ligado à origem desses aprendizes, que em sua maioria afirmavam ter raízes na Itália.

A partir do relatado pelos alunos, ficou explícito que os fatores motivadores que os orientavam tinham origem integrativa (GARDNER, 1985, apud HALL, 2011), pois havia uma identificação destes com a cultura meta, que culminou no interesse pelo aprendizado da L2 e que possibilitaria, num segundo momento, sua comunicação com os falantes de língua italiana e, por consequência, a integração desses aprendizes com a comunidade em questão. Entretanto, a mesma motivação que impulsionava o aprendizado também indicava a falta de paciência necessária para sua continuidade. Nesse aspecto, a idade representa, em primeiro lugar, experiências anteriores em sala de aula que modelam as expectativas do indivíduo; em segundo, está associada à urgência pela conclusão de seus objetivos.

Situação 2: A dinamicidade da língua

Passado o primeiro contato, chegou o momento de apresentar a língua italiana em sua constituição e história. Entretanto, essa apresentação não é em hipótese alguma uma tarefa fácil, visto que a língua italiana padrão, isto é, aquela ensinada nos cursos de idiomas, é resultado de um processo histórico que perpassa a ocupação da península itálica por diversos povos e pela unificação da Itália na segunda metade do século XIX. Dessa forma, seu estudo requer do aprendiz a abertura para as diversas possibilidades de pronúncia, de escolhas lexicais, de diferenças em relação às estruturas gramaticais e de sentido. Clarificadas essas peculiaridades, foi enfatizado que o curso não tinha como foco as estruturas linguísticas, antes, seria direcionado para a competência comunicativa num processo em longo prazo, em que as explicações mais aprofundadas da língua seriam trabalhadas de acordo com o andamento das aulas. Por conseguinte, era esperado que a classe compreendesse 
que o objetivo não era de modo algum ensinar um código estático, muito menos fornecer respostas exatas à pergunta "como se diz...?".

A princípio, alguns alunos ficaram um pouco desapontados, especialmente aqueles que já estavam de viagem marcada para a Itália, pois alimentavam a crença de que o curso lhes proporcionaria o essencial para comunicação no país durante a viagem. A frustração nítida no semblante dos alunos fez com que ficasse visível que aquela explanação tinha abalado as expectativas e crenças no que tange à velocidade do aprendizado de uma LE.

Oliveira (2008) menciona que os alunos trazem para a sala de aula uma concepção própria do que seja aprender uma língua estrangeira, o que atinge diretamente seu aprendizado. Dentre os campos associados às crenças e ressaltados pelo autor, sobressaiu nessa turma a importância do foco na tradução e na gramática para um aprendizado rápido e eficiente. De fato, havia uma necessidade por aprender frases prontas utilizadas em determinadas situações, bem como suas respectivas traduções, ou até mesmo diálogos que poderiam ser utilizados em situações rotineiras. Na medida em que avançávamos com o curso, tornava-se explícita a mudança de postura dos alunos, pois passaram a compreender que tal processo não envolve apenas a memorização de estruturas, mas, sobretudo, a compreensão de situações comunicativas.

Situação 3: Diferentes faixas etárias, diferentes expectativas.

Como mencionado nas páginas anteriores, o número inicial de inscritos sofreu variação logo nos primeiros dias do curso, quando houve a apresentação de alunos que não pertenciam à faixa da terceira idade. De acordo com a coordenadora da UNATI, a grande procura pelos cursos oferecidos por parte da comunidade abaixo dos sessenta anos fez com que o diretor do instituto permitisse, em caso de vagas remanescentes, que tais candidatos se matriculassem.

Sem dúvida, havia o conflito entre o objetivo de cada faixa etária - os mais idosos frequentavam as aulas por lazer, por isso, não se importavam em contar/ ouvir histórias, em trocar experiências, já os alunos mais jovens estavam ali para fins profissionais e por isso esperavam velocidade e dinamicidade no andamento das aulas - o que poderia prejudicar a evolução da turma. Por conseguinte, os alunos pertencentes à faixa entre os 40 e 50 anos buscavam resultados concretos que seriam alcançados por meio do seguimento estrito de um plano de aula. Em contraposição, os aprendizes que englobavam a faixa acima dos 60 anos traziam 
leveza e descontração ao curso e, embora tivessem seus objetivos, os meios para alcançá-los eram mais maleáveis, sendo o tempo um fator de menor importância.

Situação 4: A confiança no livro didático

Uma das propostas mais contestadas foi a objeção à adoção de um livro didático. Foi explicado aos alunos que as lições seriam montadas em PowerPoint e baseadas em diferentes livros, além de materiais disponibilizados na Internet. De fato, tal sugestão provocou a quebra de expectativas e desapontamento dos alunos mais jovens ao saberem que não seria adotado um único material didático a ser seguido do início ao fim do curso. Tal fato deve-se à crença sustentada pela mídia e arraigada na mente dos alunos de que o livro didático é indispensável para as aulas de língua estrangeira.

Embora a posição adotada tenha levantado uma série de questões sobre a própria qualidade do curso, foi amplamente aceito que tal opção possibilitaria aliar qualidades de diversos materiais didáticos, suprindo lacunas, oferecendo opções e, principalmente, conhecimento, para que o aluno conseguisse se comunicar em qualquer situação, e não apenas naquelas ditadas por um livro, que fornece apenas uma das muitas opções em que uma situação comunicativa pode se desenrolar. É preciso, portanto, mostrar para os alunos que aquela não é a única alternativa, mais ainda, que ela pode ser a menos frequente das possibilidades, uma variação que resulta de diferenças regionais entre o sul e o norte da Itália que estão intimamente ligadas à cultura desse país.

Um bom exemplo diz respeito ao uso das interjeições ciao e salve, que remete aos níveis de formalidade do discurso. É unanimemente aceito que a interjeição ciao pertença a níveis de discurso caracterizados pela informalidade, em contraposição a salve. Entretanto, no sul do país salve também é considerado informal e têm preferência as expressões Buongiorno e Buona sera em situações que requerem o mínimo de formalidade. Já no centro-norte do país, salve é utilizado com mais frequência nessas situações cotidianas em que não há a familiaridade entre os interlocutores. A explicação dessas discrepâncias é geralmente ignorada pelos livros didáticos.

Situação 5: Crenças e objetivos na terceira idade

Durante o curso, inúmeras foram as vezes em que os alunos mais idosos declararam que não participavam do curso para "aprender" italiano, pois sabiam que "já tinham passado da hora de aprender", que "velho não aprende mais nada 
mesmo", e que só estavam ali para "passar o tempo". Entretanto, contrariando todas as crenças e expectativas, quando expostos a uma atividade de compreensão auditiva em que foi fornecida aos alunos a letra de uma música recortada e embaralhada, e cujo objetivo era colocá-la em ordem no menor tempo possível, a aluna mais velha da turma e também a que apresentava tais crenças de forma mais arraigada teve o melhor desempenho, sobretudo se comparada aos alunos de idade inferior aos 60 anos. Além disso, os alunos idosos se mostraram mais abertos a atividades em grupo, bem como apresentaram espírito de entrosamento e motivação maiores em relação àqueles não pertencentes à terceira idade.

Uma possível explicação para tal discrepância é a seriedade atribuída ao curso pelos diferentes indivíduos. Efetivamente, a pessoa que está na faixa dos quarenta anos tem certos objetivos profissionais que dependem da sua qualificação. A aprendizagem de uma língua estrangeira contribui para o alcance de suas metas. Em compensação, o indivíduo que volta para a sala de aula como aprendiz após atingir os setenta anos tem como propósito essencial o seu bem estar físico e mental e, por conseguinte, interage de forma mais espontânea, uma vez que não há cobranças e nem mesmo a necessidade de resultados imediatos.

Situação 6: Os estereótipos

Por fim, menciono o problema da criação dos estereótipos, argumento trabalhado durante as duas últimas semanas de curso e que tem presença marcante na maioria dos livros didáticos. Como dito no item 2.1, o estereótipo reproduz uma imagem fixa de um povo, transmitida de geração para geração e, em alguns casos, disseminada globalmente, derivada de uma concepção sociológica de cultura resultante da junção entre as atividades de um povo, isto é, arte, arquitetura, teatro, dança, música, literatura (Cultura), e as crenças, a moral, os costumes, as normas e os valores (cultura) (KUMARAVADIVELU, 2008).

A cultura italiana, ou seja, a arte, a arquitetura, o teatro, a música, a literatura, os costumes desse país são amplamente difundidos, propagação esta que incentiva o turismo, a maior fonte de renda do país. Por isso, todos esses temas são, de uma forma ou de outra, abordados em livros didáticos, o que corrobora ainda mais para a disseminação de estereótipos. Quando questionados sobre quais fatores os levaram a procurar pelo curso de italiano e também o que os motivava a conhecer a Itália, todas as respostas estavam de certo modo ligadas a estereótipos. Assim, a maioria das respostas relacionava o país 1 . aos hábitos alimentares, por exemplo, a pizza, a pasta, o café, 2. à história, muitas vezes expressa na sua arquitetura; 3 . às 
músicas sentimentais ou ao teatro; 4 . ao catolicismo. Em meio à discussão sobre as generalidades em relação à cultura italiana que atravessam o globo, um dos alunos mencionou um estereótipo negativo, a saber, o da máfia.

Nesse sentido, um dos propósitos do curso foi o de desmitificar tais conceitos, apontando para a sua raiz, sua função para a economia do país, discutindo a forma como alguns deles eram abordados nos livros didáticos e em textos literários e jornalísticos que contribuem para a divulgação, algumas vezes errônea, desses estereótipos. Para tanto, foi essencial, em primeiro lugar, uma discussão sobre o conceito de cultura e o próprio conceito de estereótipo; em segundo, o reconhecimento dos estereótipos da cultura em que o aluno se insere, para que ele pudesse, posteriormente, identificar os estereótipos da cultura estrangeira e compreendê-los.

Em suma, durante os quatro meses, foram apresentadas e discutidas novas concepções de língua, cultura e até mesmo de ensino-aprendizagem. Embora não tenham sido registradas mudanças por parte dos aprendizes, foi gratificante perceber a abertura gradativa para uma nova visão de mundo. Por fim, como bem ressalta Kramsch (2010), se a cultura é discurso e, consequentemente, produção de significados, o aluno de línguas precisa saber olhar para além das palavras, refletindo sobre a interação entre discursos múltiplos e encontrando a razão de seus sentidos.

\section{CONSIDERAÇÕES FINAIS}

Sem dúvida, o trabalho com idosos é um desafio. Se por um lado a criança vê o professor como um modelo e por isso sua atuação o marcará para a vida toda, por outro, o idoso, com a sua experiência, tem vários modelos para compará-lo. O professor que leciona a idosos não só tem o papel de mediador entre o conhecimento novo e o aluno, mas, sobretudo, de mostrar contrapontos entre as suas concepções arraigadas e outras novas, esmorecer crenças, instigar a reflexão sobre o mundo que o circunda, contribuindo para o enriquecimento cultural e, consequentemente, para o desenvolvimento da sociedade em que se insere.

No tocante à relação professor-aluno idoso no processo de aprendizagem de uma língua estrangeira, é evidente que a postura do professor perante a língua e a cultura seja fundamental para a motivação do aluno, bem como para a forma como este fará uso da língua em questão, para o desenvolvimento do seu aprendizado, como também para a desconstrução de possíveis estereótipos. 
O relato de algumas ocorrências constatadas durante um curso de língua italiana para alunos da terceira idade aponta para a congruência entre o ambiente de sala de aula com estudos que abordam a temática do ensino de línguas para esse público. A explanação da maneira como as crenças, os valores, a motivação e a concepção de cultura estiveram presentes no decorrer do curso demonstra a importância do papel de cada um desses fatores na evolução do aprendizado.

Por fim, convém enfatizar que, apesar de desafiador, o ensino para alunos idosos é altamente gratificante, não apenas pela troca de conhecimento e experiências, mas, sobretudo, pelo reconhecimento por parte dos alunos do trabalho e dedicação do professor de língua estrangeira e de sua importância no cenário atual.

\section{REFERÊNCIAS BIBLIOGRÁFICAS}

BARCELOS, A.M.F. (2004) Crenças sobre aprendizagem de línguas, Lingüística Aplicada e ensino de línguas. Linguagem \& Ensino, v. 7, n. 1, p.123-156.

HALL, G. (2011) Exploring English Language Teaching: Language in Action. New York: Routledge. HALU, R.C.; PARANÁ, J.M. (2007) Análise de conflito de crenças sobre o aprendizado de línguas estrangeiras: o aluno adulto na crise do nível intermediário. Revista $X$, v. 1, n.0.

HOUAISS, A. (2009) Dicionário Eletrônico Houaiss da Lingua Portuguesa. Versão 1.0. Editora Objetiva.

JIN, L.; CORTAZZI, M. (1998) The culture the learner brings: a bridge or a barrier? In: BYRAM, M.; FLEMING, M. (Ed.) Language Learning in Intercultural Perspective. Cambridge, CUP.

KRAMSCH, C. (2010) The symbolic dimensions of the intercultural. Plenary Speech at the Second International Conference on the Development and Assesssment of Intercultural Competence at the University of Arizona, Tucson, Arizona, USA.

KUMARAVADIVELU, B. (2008) Cultural Globalization and Language Education. New Haven, CT.: Yale University Press.

KUMARAVADIVELU, B. (2012) Language Teacher Education for a Global Society: a modular model for knowing, analyzing, recognizing, doing and seeing. New York: Routledge.

NASCENTE, R.M.M. (2006) A Influência da interação entre estilos de ensino e aprendizagem no rendimento de estudantes adultos de língua inglesa. Estudos Linguísticos, v. 35, p. 1650-1659.

OLIVEIRA, H. F. (Jan./Dez. 2007/2008) Percepções de adultos sobre aprender língua inglesa. Poiésis Pedagógica. Revista do Departamento de Pedagogia da Universidade Federal de Goiás - Campus Catalão, v.5/6, p. 147-166.

PEREIRA, E. T. O idoso e o aprendizado de uma nova lingua: o descortinar de trocas sociais e afetivas. Dissertação. (Mestrado em Gerontologia Social). Programa de Estudos Pós- 
Graduados em Gerontologia Social. Pontifícia Universidade Católica de São Paulo, São Paulo. 2005.

SALOMÃO, A.C.B. (2012) A cultura e o ensino de língua estrangeira: perspectivas para a formação continuada no projeto Teletandem Brasil. Tese de Doutorado em Estudos Linguísticos, Instituto de Biociências, Letras e Ciências Exatas, Universidade Estadual Paulista, São José do Rio Preto.

SCHLEPPEGRELL, M. (1987) The Older Language Learner. Washington, D,C.: ERIC Clearinghouse on Language and Linguistics. Acesso em jul. 2013. Disponível em $<$ http://files.eric.ed.gov/fulltext/ED287313.pdf $>$.

SCHÜTZ, R. (2003) Motivação e Desmotivação no Aprendizado de Línguas. English Made in Brazil. Disponível em: <http://www.sk.com.br/sk-motiv.html>. Acesso em 02 de julho de 2013.

SERRONHA, M.M.B. (2010) Aprendizagem do inglês na idade adulta: percepçôes de especialistas, formadores e formandos. Especialização em Educação e Formação de Adultos, Universidade do Algarve, Faro.

VINTRO DE DEUS, N.A. (2007) Adulto: aluno infiel ou incompreendido? Aspectos linguiísticos, sociais e afetivos que permeiam o ensino da língua inglesa (LE) para adultos. Dissertação. (Mestrado em Linguística Aplicada) - Instituto de Letras, UnB, Brasília.

Recebido: $17 / 08 / 2016$

Aceito: 13/02/2017 